\title{
A Double-Blind Placebo-Controlled Trial of sertraline (stimuloton) for treatment Shopping addiction
}

\author{
Aliyev NA ${ }^{1 *}$ and Aliyev $\mathbf{Z N}^{2}$ \\ ${ }^{1}$ Azerbaijan State Advanced Training Institute for Doctors named by A. Aliyev, department of psychiatry and addiction, Baku, Azerbaijan \\ ${ }^{2}$ Azerbaijan Medical University, department of psychiatry, Baku, Azerbaijan
}

\begin{abstract}
Objectives: The effects of sertraline (stimuloton) and placebo for treatment Shopping addiction.

Materials and methods: 50 patients suffering from Shopping addiction and 50 healthy subjects were examined at the Ministry of Health's Mental Health Center by YBOCS-SV score. Fifty were randomly assigned to sertraline $(n=50)$ or placebo $(n=50)$. Patients should be given $50 \mathrm{mg}$ in the first week, $50 \mathrm{mg}$ on week 2 weekly - 50mg, 3rd week $150 \mathrm{mg} /$ day and 5th week - 24th weeks, $200 \mathrm{mg}$ in the day (100mg in the morning and $100 \mathrm{mg}$ evening) sertraline. Placebo group was given indifferent tablets in the same time.

Results: The results were measured prior to and after treatment with the Student $t$ criterion. YBOCS-SV scores were $25.6 \pm 4.0$ before treatment, and $6.2 \pm 3.5$ at the end of the treatment. Thus at the end of the treatment, Student $t=8.55$, the degree of freedom $\mathrm{df}=23, \mathrm{p}<0.001$, ie the results obtained were statistically valid. A side effect during stimulation was recorded when patients were called by themselves. 12 -month catamnesis observation showed that $20 \%$ of patients had a relapse.

Conclusions: treatment by sertraline group of Shopping addiction compared to placebo, resulted in significantly greater improvement in YBOCS-SV score. Side effects headache and perspiration often were observed in sertraline group.
\end{abstract}

\section{Introduction}

Addiction (English addiction - addictive, very damaging habit, meaningfulness) is a requirement of a person in a broad sense. The term is often used in the expression of dependence on psychoactive substances (PAM). But lately, this term is often used in terms of nonchemical, or psychological dependency. Grooming addiction involves non-chemical addictive disorders. It should be noted that behavioral addiction is so urgent that this violation was included in DSM-5 [1] Substance Use and Addictive Disorders (Psychoactive Substance Use and Addictive Disorders). Here, in the first place, we talk about gambling - gambling. Recently, this section has been debated about including other non-chemical dependencies - including sexual, internet, baseline addictions. Shopping addiction, i.e. Shopping addiction addiction, is called onionism (Greek onionism: onion-derived, mania-driven tendency).

For the first time in 1902, the term oniomia was proposed by $\mathrm{E}$. Kraepel. E. Bleuler shows that Krepel's class of impulsive psychosis classified onionism, pyromania and kleptomania [2]. It is known that the compulsive shopping addiction is not shown as a diagnostic either in the XBT-10 or DSM-5. According to Black, the compulsive Shopping addiction should be classified into both categories, since the violation is a clinical phenomenon [3].

According to the literature, the compulsory Shopping addiction accounts for $2-8 \%$ of the total population, with $80-95 \%$ of them being women [4].

The role of psychopharmacotherapy in the treatment of compulsive shopping addiction is uncertain [5]. Some studies have shown that antidepressants are effective, especially for fluvoxamine, which is a selective inhibitor of serotonin reuptake (SGASI) [6]. But, so far, effective treatment of compulsive shopping addiction is unknown.

Thus, on the one hand, the extensive spread of compulsory shopping addiction among the population and, on the other hand, the treatment of this disorder is becoming an urgent problem. The aim of this study was to evaluate the effectiveness of sertraline (stimulator) in the treatment of compulsive shopping addiction for 24 weeks.

\section{Material and method of research}

50 patients suffering from Shopping addiction and 50 healthy subjects were examined at the Ministry of Health's Mental Health Center by YBOCS-SV score. Fifty were randomly assigned to sertraline $(n=50)$ or placebo $(n=50)$. Patients should be given $50 \mathrm{mg}$ in the first week, $50 \mathrm{mg}$ on week 2 weekly - 50mg, 3rd week $150 \mathrm{mg} /$ day and 5 th week - 24th weeks, $200 \mathrm{mg}$ in the day (100mg in the morning and $100 \mathrm{mg}$ evening) sertraline. Placebo group was given indifferent tablets in the same time. 50 patients suffering from compulsive Shopping addiction were examined at the Ministry of Health's Mental Health Center. The diagnosis of compulsive Shopping addiction was designated by McElroy,

*Correspondence to: Nadir A Aliyev, professor, Department of Psychiatry and Addiction Azerbaijan State Advanced Training Institute for Doctors named by A. Aliyev, department of psychiatry and addiction, Baku, Azerbaijan; Baku City, U. Chagibekov Street, 46/50, F. 1. Baku P.O. AZ0010 Azerbaijan Republic, E-mail: aliyevnadir@yahoo.com

Key words: sertraline, treatment Shopping addiction

Received: August 18, 2018; Accepted: September 17, 2018; Published: September 20, 2018 
et al. [7]. All the inspected were women. Written consent was made in the family of patients who were included in the study. The median mean age was $\mathrm{SD}=42.7 \pm 7.0$ years, mean age of compulsive Shopping addiction mean $\pm \mathrm{SD}=22.6 \pm 7.1$. Bipolar affective disorder, psychotic states and other somatic and mental illnesses were excluded from the reviewed patients placebo. Patients should be given $50 \mathrm{mg}$ in the first week, $50 \mathrm{mg}$ on week 2 weekly - 50mg, $3 \mathrm{rd}$ week $150 \mathrm{mg} /$ day and 5 th week - 24th weeks, $200 \mathrm{mg}$ in the morning (100mg in the morning and $100 \mathrm{mg}$ ) sertraline (stimulotone). The mean dose of treatment was 200 $\pm 20.5 \mathrm{mg}$. The effectiveness of the treatment was determined by the Yale-Brown Obsessive Compulsive Scale-Shopping Version (YBOCSSV) scale [8]. The assessment of the condition of patients on this scale was carried out at 1, 2, 3, 4, 8, 12, 16, 20, 24 weeks. The positive effect of the treatment was that the YBOCS-SV score was $75 \%$ lower than the initiation. (Table 1)

\section{Results}

The results were measured prior to and after treatment with the Student $\mathrm{t}$ criterion. YBOCS-SV scores were $25.6 \pm 4.0$ before treatment, and $6.2 \pm 3.5$ at the end of the treatment. Thus at the end of the treatment, Student $t=8.55$, the degree of freedom $\mathrm{df}=23, \mathrm{p}<0.001$, i.e. the results obtained were statistically valid. An side effect during stimulation was recorded when patients were called by themselves. 12 -month catamnesis observation showed that $20 \%$ of patients had a relapse. (Table 2)

\section{Discussion}

Ben Hague, et al. [8] wrote: "Large effect sizes were found for SSRI antidepressant medication. However, SSRIs did not show significant superiority in terms of efficacy when treating CBD compared with placebo. Interestingly, the SSRI's citalopram and escitalopram (which share the same active compound) showed contradictory findings. Further high-quality research into the role of SSRIs in treating CBD is required; particularly as these studies currently constitute a large proportion of the current pharmacotherapy evidence base".

This author there systematic and meta-analytical review showed that the results of CBD studies draws the following conclusions: (a)

Table1. The socio-demographic characteristics of the control and placebo gurp patients were given in the table 1

\begin{tabular}{|c|c|c|c|c|}
\hline Characteristic & \multicolumn{2}{|c|}{ Sertraline group* } & \multicolumn{2}{c|}{ Placebo group } \\
\hline All sex females & 50 & 30 \\
\hline Family status: & 72 & 6 & 64 \\
\hline Married with & 36 & 8 & 12 & 12 \\
\hline Divorced & 4 & 20 & 36 & 72 \\
\hline Single & 10 & 68 & 8 & 6 \\
\hline Professions: & 34 & 20 & 6 & 12 \\
\hline Works & 10 & 12 & & \\
\hline Not working & 6 & & \\
\hline Student & &
\end{tabular}

*Statistical confidence between the control and placebo groups is absent

Table 2. Side effects of the treatment in the control and placebo gurp

\begin{tabular}{|c|c|c|c|c|}
\hline Side effects & \multicolumn{2}{|c|}{ Control group } & \multicolumn{2}{c|}{ Placebo group } \\
\hline & Abs. & $\%$ & Abs. & $\%$ \\
\hline Dizziness & 8 & 16 & 6 & 12 \\
\hline Headache & 16 & 32 & 12 & 24 \\
\hline Fatigue & 8 & 16 & 5 & 10 \\
\hline Perspiration & 16 & 32 & 10 & 20 \\
\hline Nausea & 8 & 16 & 10 & 20 \\
\hline Sleepiness & 8 & 16 & 2 & 4 \\
\hline
\end{tabular}

the evidence base for CBD treatments is somewhat undermined by inconsistent study quality and the risk of publication bias; research and risk of bias publications; (b) (b) both psychotherapy and pharmacotherapy treatments have been studied somewhat haphazardly and sporadically across the stages of the hourglass model; (c) the large size of the effect before fasting in high-quality studies of group psychotherapy demonstrates the promise of this approach; (d) large uncontrolled dimensions of the effect for the treatment of drugs are undermined because of poor methodological quality; (e) there is a significant placebo effect when treating a CBD with a drug; and finally, (f) the lack of significant practical research (stage 3 hourglass) is appropriate, given the scarcity of controlled studies of psychotherapy and pharmacotherapy in phase 2 of the hourglass model."

We agree whit they author that, SSRI citalopram requires further controlled study to build on promising outcomes. Clearly, CBD remains an under-recognized and challenging clinical disorder to treat. Ensuring and improving the methodological quality of future studies will improve confidence in the initial evidence that compulsive buyers can manage their compulsions to spend through relatively short-term theory-based psychotherapeutic interventions.

This study is a limitation of the number of patients and little time of observation. Nevertheless, during the 24 weeks of sertraline, treatment results show that $80 \%$ of the patients had a permanent remission. We concluded that, our results consilience with other investigates, who treated shopping addiction by fluxamine [9] and citalopram [10].

\section{Conclusion}

The sertraline treatment of compulsive Shopping addiction has been safe and effective. Long-term double-blind placebo-controlled investigations are needed with other SGASI. In conclusion, it should be noted that the most promising is the search for drugs for the therapy of Shopping addiction among both classical and new antidepressants in combination with psychotherapy.

\section{Authors' contribution}

Final manuscript was approved by all authors.

\section{Conflict of interest}

The authors declare no conflict of interest

\section{Funding statement}

No financial support was received for this study.

\section{References}

1. Diagnostic and statistical manual of mental disorders. (5th Edn) (DSM V).

2. Bleuler E (1920) Руководство по психиатрии. Берлин: Изд. товарищества Врач.

3. Black DW (2007) Compulsive buying disorder: a review of the evidence. CNS Spectr 12: 124-132. [Crossref]

4. Black DW (1996) Compulsive buying: a review. J Clin Psychiatry 57 Suppl 8: 50-54 [Crossref]

5. Koran LM (1999) Obsessive - Compulsive and Related Disorders in Adults: A Comprehensive Clinical Guide. Cambridge, England Cambridge University Press.

6. Ninan PT, McElroy SL, Kane CP, Knight BT, Casuto LS, et al. (2000) Placebocontrolled study of fluvoxamine in the treatment of patients with compulsive buying. $J$ Clin Psychopharmacol 20: 362-366. [Crossref]

7. McElroy SL, Keck PE Jr, Pope HG Jr, Smith JM, Strakowski SM (1994) Compulsive buying: a report of 20 cases. J Clin Psychiatry 55: 242-248. [Crossref]

8. Hague B, Hall J, Kellett S (2016) Treatments for compulsive buying: A systematic review of the quality, effectiveness and progression of the outcome evidence. J Behav Addict 5: 379-394. [Crossref] 
9. Monahan P, Black DW, Gabel J (1996) Reliability and validity of a scale to measure change in persons with compulsive buying. Psychiatry Res 64: 59-67. [Crossref]
10. Koran LM, Bullock KD, Hartston HJ, Elliott MA, D’Andrea V (2002) Citalopram Treatment of Compulsive Shopping: An Open-Label Study. JClin Psychiatry 63: 704708. [Crossref]

Copyright: (C2018 Aliyev NA. This is an open-access article distributed under the terms of the Creative Commons Attribution License, which permits unrestricted use, distribution, and reproduction in any medium, provided the original author and source are credited. 